\title{
A Rare Combination of Complex Congenital Heart Disease with Acquired Rheumatic Valvular Heart Disease
}

\author{
Abdul Wadud Chowdhury ${ }^{1}$, Azizul Haque ${ }^{1}$, ABM Imam Hosen², Gias Uddin Md salim¹, \\ Kazi Nazrul Islam ${ }^{1}$, Mohammod Gaffar Amin ${ }^{1}$, Abu Taher Md. Mahfuzul Hoque ${ }^{1}$, \\ Md. Khalequzzaman ${ }^{1}$, Pratyay Hasan ${ }^{3}$ \\ ${ }^{1}$ Department of Cardiology, Dhaka Medical College, Dhaka, ${ }^{2}$ Department of Cardiology, Jhalakati \\ Sadar Hospital, Jhalakati, ${ }^{3}$ Department of Medicine, Dhaka Medical College, Dhaka
}

Keywords: Tetralogy of Fallot, Rheumatic fever, Congenital heart disease

\section{Abstract:}

Tetralogy of Fallot (TOF) is a complex cyanotic congenital heart disease with a survival beyond middle age. Rheumatic and congenital cyanotic heart disease are common causes of hospital admission. However, coexistence of rheumatic heart disease with complex congenital heart disease like TOF is known to occur very rarely. This report presents a case of rheumatic valvular heart disease (AR \& MR) with a complex congenital heart disease (TOF with PDA with PLSVC) in a 30 yrs old female. Patient was treated by conservative management and advised for corrective surgery and double valve replacement.

(Cardiovasc j 2021; 13(2): 235-238)

\section{Introduction:}

There has been a substantial increase in prevalence of congenital heart disease (CHD) all across the world in the past decades, perhaps because of increase availability of imaging facilities. ${ }^{1}$ In fact, the reported prevalence of total CHD has increased from 0.6 per 1,000 live births (95\% confidence interval [CI]: 0.4 to 0.8 ) in 1930 1934 to 9.1 per 1,000 live births (95\% CI: 9.0 to 9.2 ) after $1995 .{ }^{1}$ Again, reported total CHD birth prevalence in Asia was significantly higher compared with all other continents (9.3 per 1,000 live births [95\% CI: 8.9 to 9.7], $\mathrm{p}<0.001) .{ }^{1}$ In a systematic review and meta-analysis published in 2011, comprising 114 studies, worldwide prevalence of Tetralogy of Fallot (TOF) was found to be 0.34 (95\% CI: 0.31 to 0.37 ) per 1000 live births and that of patent ductus arteriosus (PDA) was 0.87 (95\% CI: 0.83 to 0.91$).{ }^{1}$ In USA, the prevalence of TOF was estimated to be 0.93 per 1000 live births. ${ }^{2}$ In Bangladesh, Fatema et al. reported that the prevalence of TOF was $14 \%$ among other CHDs. ${ }^{3}$ Recently in 2018, Nagasawa et al reported that the incidence of persistent left superior vena caca (PLSVC) in normal neonates was 0.21\% (95\% confidence interval $0.042-0.38 \%$ ) and it is higher (more than 7.0 times the incidence in normal subjects) in all CHD patients. ${ }^{4}$ The prevalence of rheumatic heart disease (RHD) in Bangladesh is $0.3 / 1000 .{ }^{5}$ Coexistence of rheumatic heart disease with Tetralogy of Fallot is known to occur very rarely. ${ }^{6,7}$ This article reports a case of an interesting association of rheumatic mitral and aortic regurgitation in an adult with TOF (doubly committed VSD, $45 \%$ overriding of aorta, valvular PS \& RV hypertrophy) associated with PDA \& PLSVC.

\section{Case Report}

A 30-year-old 37 weeks pregnant woman was admitted in the coronary care unit (CCU) in Dhaka Medical College \& Hospital with the complaints of

Address of correspondence: Prof. Abdul Wadud Chowdhury, Department of Cardiology, Dhaka Medical College, Dhaka, Bangladesh. Email-

๑ 2020 authors; licensed and published by International Society of Cardiovascular Ultrasound, Bangladesh Chapter and Bangladesh Society of Geriatric Cardiology. This is an Open Access article distributed under the terms of the CC BY NC 4.0 (https://creativecommons.org/licenses/by-nc/4.0) 
worsened breathlessness for two weeks with orthopnea and generalized bluish discoloration of whole body. Her mother mentioned that the patient had ill health since birth with a history of low birth weight, who became bluish and had respiratory distress during breast feeding, used to cry during exertion and had delayed developmental milestones. The patient started to sit at the age of one year and could stand at the age of 3 years. The patient also had history of acute onset of fever with migratory polyarthritis at 10 years of age without any history of involuntary movements or any skin changes. She was reviewed by a cardiologist at that time and was diagnosed as a case of acute rheumatic fever and got treatment, but she could not show any medical records. However, she mentioned that she had been treated with tab. Phenoxymethyl penicillin (250mg B.D) for a few years.

She was married at the age of 20 years and had history of two abortions and now she has one surviving child aged 18 months. This was her $4^{\text {th }}$ gravida. All members of her family are healthy.

On general examination, the patient was illlooking, small-built individual with mild anemia, generalized clubbing (grade 3) and central cyanosis. Her blood pressure was 100/60 mm Hg (on both arms), pulse- 98 beats/min, regular, with normal volume; JVP was not raised \& edema was absent. In room air, oxygen saturation was $86 \%$.

On precordial examination, apical impulse, suprasternal and supraclavicular pulsations were present. Apex beat was located in the left $6^{\text {th }}$ intercostal space lateral to the midclavicular line, which was forceful and ill sustained. Left parasternal lift was present. On auscultation, first heart sound was soft, second heart sound was single
$\&$ loud. There was a pan systolic murmur (grade $3 / 6$ ) in the mitral area radiating towards the axilla and also, an ejection systolic murmur in the pulmonary area radiating to left infra-clavicular area (grade $3 / 6$ ) and an early diastolic murmur on left $3^{\text {rd }}$ and $4^{\text {th }}$ intercostal space (grade $3 / 4$ ). On admission, lungs showed bilateral pulmonary crepitations up to mid-zone. Fetal heart sounds were normal. Other systemic examinations were normal.

Investigations showed Hb-10.2 gm/dl, ESR- 65 mm in 1st hour, normal total and differential count of WBC. PBF showed microcytic hypochromic anemia. Iron profile showed S. Ferritin-22.12 ng/ $\mathrm{ml} \&$ TIBC-363 microgram/dl. ECG showed biventricular hypertrophy with RAD \& bi-atrial enlargement. CXR showed cardiomegaly with plethoric lung fields. Fetal sonography showed healthy single fetus of about 37 weeks' size.

The echocardiogram showed a large mal-aligned doubly committed ventricular septal defect (VSD) with $45 \%$ aortic override. Rheumatic changes in the mitral leaflets (thickened, echogenic leaflet, sub-valvular changes) were seen and aortic cusps were thickened and echogenic along with prolapse of NCC. Dilated coronary sinus indicates presence of PLSVC (Figure1 \& 2). There was moderate mitral regurgitation with a posteriorly directed jet and moderate eccentric aortic regurgitation due to NCC prolapse (Figure 3 and 4). There was also patent ductus arteriosus (PDA) and persistent left superior vena cava (PLSVC) associated with TOF (Figure $1 \& 5$ ). She also had valvular pulmonary stenosis (PS) with right ventricular hypertrophy (Figure 6) and hypoplastic main pulmonary artery with normal size confluent branch pulmonary arteries. The final diagnosis was a case of complex congenital heart disease including TOF with PDA with PLSVC and rheumatic mitral and aortic

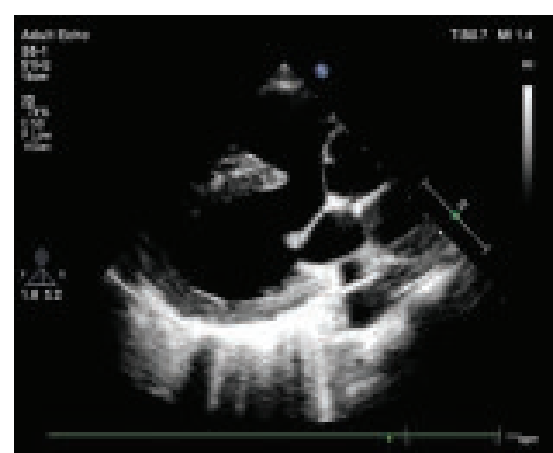

Fig.-1: PLAX showed VSD.

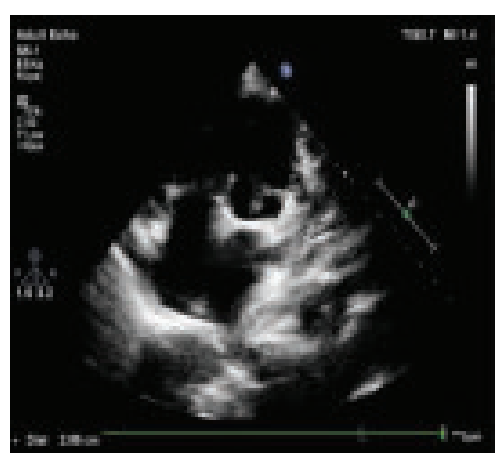

Fig.-2: PSAX showed large VSD.

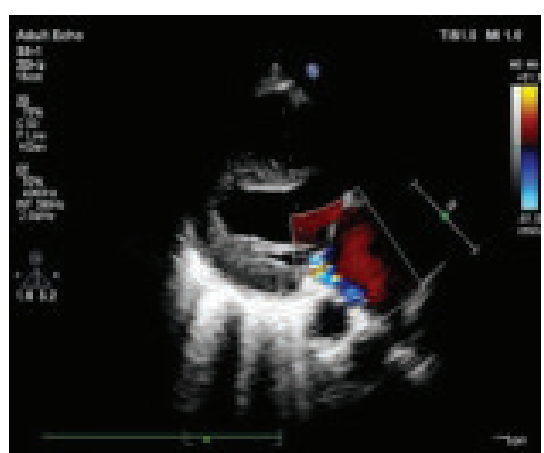

Fig.-3: CFM showed eccentric MR 


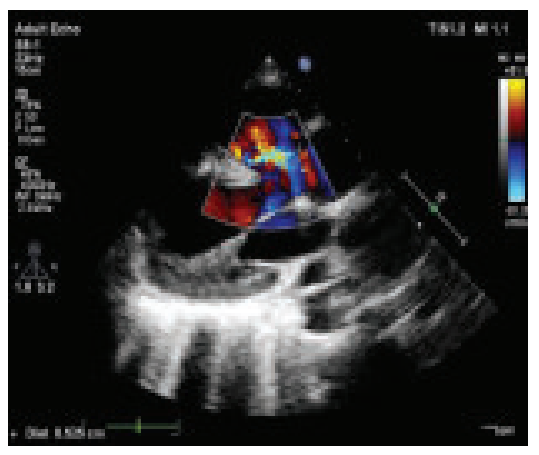

Fig.-4: CFM showed eccentric $A R$

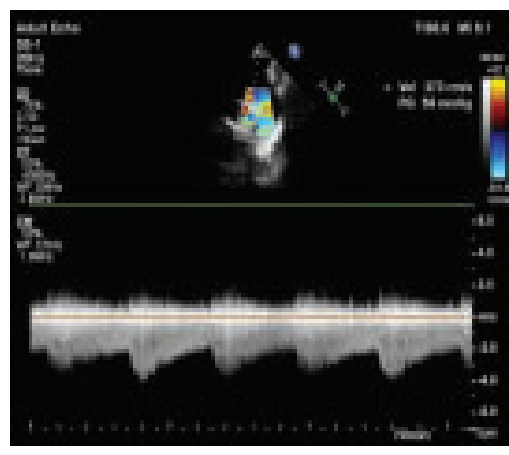

Fig.-5: Spectral Doppler showed picket Fence appearance

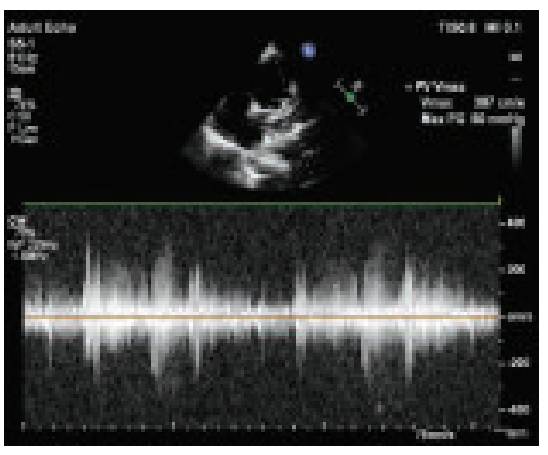

Fig.-6: Spectral Doppler showed $P S$. regurgitation with pulmonary congestion with 37 weeks pregnancy.

The patient was treated with high flow $\mathrm{O}_{2}$, restriction of fluid, cautious administration of diuretics for short duration, propranolol, phenoxymethyl penicillin and inj. ceftriaxone, irons \& vitamins. During discharge, propranolol, phenoxymethyl penicillin vitamins + iron were given and she was advised to avoid further pregnancy until corrective surgery of TOF and double valve replacement with metallic prosthesis of mitral and aortic valve are done. She underwent normal vaginal delivery in the hospital under close supervision of obstetricians \& cardiologists \& she delivered a healthy male baby.

\section{Discussion:}

Rheumatic involvement of heart complicating Tetralogy of Fallot was reported several times in medical literature, mostly in India. ${ }^{8-10}$ Association of RHD with PDA is more uncommon and found only in a few case reports. ${ }^{11,}{ }^{12}$ Association of multiple conditions such as, RHD with TOF and PDA with PLSVC was not found before in available literature by this group of researchers, and this may be the index case of such a combination of features.

About $50 \%$ of patients with rheumatic heart disease may not have a prior history of rheumatic fever, ${ }^{13}$ although, our patient had history of acute onset of fever with migratory polyarthritis.

In TOF, a large malaligned nonrestrictive perimembranous VSD is usual \& Infundibular PS is common (about $75 \%$ cases). Our case had doubly committed VSD \& valvular PS(which occur in 20$25 \%$ cases). ${ }^{14}$ This patient also had hypoplastic MPA but normal size confluent branch pulmonary arteries due to PDA.
Volume overload was present as a result of MR, $\mathrm{AR}$ and PDA. Our patient presented with hyperdynamic circulation potentiated by anemia with passive pulmonary venous congestion that caused breathlessness. Her echocardiography showed ejection fraction of $62 \%$, which indicates that peripartum cardiomyopathy did not occur. LA \& LV were dilated due to MR, AR, \& PDA. The patient became symptomatic due to volume overload along with hyperdynamic circulation during pregnancy aggravated by anemia.

Coexistence of rheumatic heart disease with Tetralogy of Fallot is rare. ${ }^{6,7}$ Only a few case reports regarding rheumatic mitral and aortic regurgitation with Tetralogy of Fallot (TOF) in developed and developing countries are found; although none was available in Bangladesh. This report draws attention to an interesting association of rheumatic mitral and aortic regurgitation in an adult with TOF, PDA and PLSVC and highlights the possibility of coexistent rheumatic lesion in patients with congenital heart disease.

\section{Conclusion:}

This report adds another instance of growing collection of cases presenting with different combinations of congenital \& acquired cardiac defects. This case report should draw attention to clinicians and researchers alike to such rare combination of multiple heart defects.

\section{Conflict of Interest - None.}

\section{References}

1. van der Linde D, Konings EEM, Slager MA, Witsenburg M, Helbing WA, Takkenberg JJM, et al. Birth prevalence of congenital heart disease worldwide: a systematic review and meta-analysis. J Am Coll Cardiol 2011 Nov 15; 58(21):2241-2247. 
2. Centers for Disease Control and Prevention (CDC). Improved national prevalence estimates for 18 selected major birth defects-United States, 1999-2001. MMWR Morb Mortal Wkly Rep 2006 Jan 6; 54(51):1301-1305.

3. Fatema NN, Chowdhury RB, Chowdhury L. Incidence of Congenital Heart Disease among Hospital Live Birth in a Tertiary Hospital of Bangladesh. Cardiovasc J 2008; 1(1):14-20.

4. Nagasawa H, Kuwabara N, Goto H, Omoya K, Yamamoto T, Terazawa A, et al. Incidence of Persistent Left Superior Vena Cava in the Normal Population and in Patients with Congenital Heart Diseases Detected Using Echocardiography. Pediatr Cardiol 2018 Mar; 39(3):484-490.

5. Zaman M. Trend of Rheumatic Heart Disease Prevalence in Bangladeshi Children. Ann Vasc Med Res 2016; 3(3):1035.

6. Bokhandi SS, Tullu MS, Shaharao VB, Bavdekar SB, Kamat JR. Congenital heart disease with rheumatic fever and rheumatic heart disease: a coincidence or an association? J Postgrad Med 2002 Jul 1; 48(3):238.

7. Mohan JC, Arora R, Khalilullah M. Double outlet right ventricle with calcified rheumatic mitral stenosis. Indian Heart J 1991 Oct; 43(5):397-399.

8. Mansur Aj, Grinberg M, Lopes Ea, et al. Acute rheumatic involvement of the 4 cardiac valves in a patient with tetralogy of Fallot. Arq Bras Cardiol 1980 Dec 1; 35(6):499-502.

9. Sai Krishna C, Reddy GV, Debta M, Panigrahi NK. Tetralogy of Fallot with rheumatic mitral stenosis: a case report. J Med Case Rep 2008 Apr 28; 2:127.

10. Bhaya M, Beniwal R, Panwar RB. Acute Rheumatic Fever Complicating Tetralogy of Fallot. Scholarly Research Exchange 2008; 2008:1-4.

11. Sahoo D, Kumar S, Kapoor A. Silent patent ductus arteriosus incidentally found before balloon mitral valvotomy for severe rheumatic mitral stenosis. $J$ Cardiol Cases 2016 Jun; 13(6):165-168.

12. Patra S, Kumar B, Sadananda KS, Krishnappa S, Basappa H, Nanjappa MC. Juvenile severe mitral stenosis predisposing Eisenmenger syndrome in a case with ventricular septal defect, patent ductus arteriosus, coarctation of aorta \& hypoplastic aortic arch: Report of first case of rare association. J Cardiovasc Dis Res 2013 Sep; 4(3):195-197.

13. Kumar RK, Tandon R. Rheumatic fever \& rheumatic heart disease: The last 50 years. Indian J Med Res 2013 Apr; 137(4):643-658.

14. Satpathy M, Misra BR. Clinical diagnosis of congenital heart disease [Internet]. 1st Ed. New Delhi: Jaypee Bros. Medical Publishers; 2008 [cited 2020 Feb 10]. 258 of 392. Available from: http://public.ebookcentral. proquest.com/choice/publicfullrecord.aspx?p=792874 